\title{
PENGARUH BUDAYA ORGANISASI DAN KARAKTERISTIK INDIVIDU TERHADAP KOMITMEN ORGANISASI PADA PT. NUSANTARA AUTO PARTS
}

\author{
Marvin $^{1}$ \\ Program Studi Manajemen STMB Multismart \\ Jalan Merbabu Dalam No. 32 aa-bb Kota Medan \\ marvinzhow@gmail.com \\ Latersia Br Gurusinga ${ }^{2}$ \\ Program Studi Manajemen STMB Multismart \\ Jalan Merbabu Dalam No. 32 aa-bb Kota Medan \\ latersiabrgurusinga@stmb-multismart.ac.id
}

\begin{abstract}
Abstrak
The purpose of this study was to determine and analyze the work environment and career development effect on organizational commitment partially and simultaneously. The research used is research with quantitative methods. The technique of collecting data in this study was done by distributing questionnaires. The data analysis technique in this study used the classical assumption test, multiple regression, hypothesis testing with SPSS 22 software. The population in this study was 56 employees at PT. Nusantara Auto Parts. From the research results obtained tcount $<$ ttable (6.606 > 1.68), meaning that the work environment has a significant effect on organizational commitment. Likewise with the career development variable obtained tcount $<$ ttable (7.144 > 1.68), meaning that career development has a significant effect on organizational commitment. Based on the results of the F test, it shows that Fcount $>$ Ftable $(41.716>3.26)$ and a value of $0.000<0.05$, this indicates that simultaneously the work environment and career development have a significant effect on organizational commitment.
\end{abstract}

Kata Kunci Work Environment, Career Development, Organizational Commitment

\section{PENDAHULUAN}

Dalam perkembangan zaman pada saat ini, berbagai macam aspek keunggulan dibutuhkan oleh setiap perusahaan dalam rangka mencapai tujuannya. Perusahaan sangat memerlukan adanya suatu potensi dan kekuatan internal yang kokoh dalam rangka menghadapi semua tantangan, hambatan serta perubahan yang ada. Faktor utama yang dibutuhkan dalam rangka mewujudkan harapan tersebut adalah faktor sumber daya.

Penilaian sumber daya manusia dapat dilihat dari hasil kerja yang telah dilakukannya melalui Komitmen Organisasi yang dihasilkannya. Sehingga dapat dikatakan sumber daya manusia yang efektif itu menghasilkan Komitmen Organisasi yang baik. Pentingnya memperhatikan Komitmen Organisasi karyawan sebab karyawan termasuk sumber daya utama dan aset penting dalam perusahaan. Perusahaan harus dapat menjaga atau bahkan meningkatkan kualitas karyawannya sehingga karyawannya dapat membuahkan Komitmen Organisasi yang baik.

Komitmen Organisasi yang tinggi perlu didukung dengan aktivitas karyawan yang melebihi harapan. Faktor yang mempengaruhi Komitmen Organisasi kerja yaitu adanya komitmen organisasi yaitu budaya organisasi. Budaya organisasi dapat meningkatkan Komitmen Organisasi karyawan dalam perusahaan, sehingga karyawan dapat menyelesaikan tugas sesuai dengan jabatan dan posisi mereka. Budaya organisasiyang kondusif dan nyaman merupakan suatu 
pendorong bagi karyawan agar bekerja lebih giat dan sungguh sungguh dalam mencapai tujuan yang diinginkan.

Selain Budaya organisasi, faktor yang mempengaruhi Komitmen Organisasi yaitu Karakteristik individu. Perlu diketahui bahwa setiap perusahaan akan memiliki Karakteristik individu yang berbeda. Keanekaragaman pekerjaan yang dirancang di dalam perusahaan, atau sifat individu yang ada akan menggambarkan perbedaan tersebut. Karakteristik individu penting untuk diciptakan karena merupakan persepsi seseorang tentang apa yang diberikan oleh perusahaan dan dijadikan dasar bagi penentuan tingkah laku anggota selanjutnya.

Karakteristik individu dapat mempengaruhi karyawan dalam memproduksi barang atau jasa. Oleh karena itu, Karakteristik individu diperlukan untuk meningkatkan keterampilan atau kemampuan karyawan dalam bekerja dan untuk meningkatkan menyelesaikan pekerjaan yang ditugaskan kepada mereka. Dapat disimpulkan bahwa didalam suatu karakteristik individuakan mempengaruhi perilaku para karyawan dan membentuk kerjasama antar karyawan untuk mencapai tujuan bersama didalam perusahaan.

Berdasarkan hasil observasi menunjukkan bahwa banyak usia karyawan di PT. Nusnatara Auto Parts di dominasi oleh karekteristik individu yang usianya sudah mencapai $>40$ tahun namun dalam penyelesaian pekerjaan tidak tepat waktu, sementara karekateristik individu 2-5 tahun dalam menyelesaikan pekerjaan tepat waktu, hal ini menunjukkan bahwa usia yang lebih muda lebih bersemangat dalam menyelesaikan pekerjaan

Berdasarkan latar belakang masalah di atas maka tujuan penelitian ini adalah untuk mengetahui dan menganalisis secara parsial dan simultan pengaruh budaya organisasi dan karakteristik individu terhadap komitmen organisasi pada PT. Nusantara Auto Parts.

\section{LANDASAN TEORI}

Kinerja pada umumnya diartikan sebagai kesuksesan seseorang dalam melaksanakan suatu pekerjaan. Kinerja karyawan merupakan hasil kerja yang dicapai seseorang dalam melaksanakan tugas-tugas yang dibebankan kepadanya untuk mencapai target kerja. Kinerja karyawan merupakan salah satu faktor penentu keberhasilan perusahaan atau organisasi dalam mencapainya (Lomanjaya, 2012).

Karakteristik individu yang dimiliki seseorang, unik atau berbeda satu dengan yang lainnya. Menurut Robbins (2008), bahwa variabel ditingkat individu meliputi karakteristik biografis, kemampuan, kepribadian, proses belajar, persepsi, sikap dan kepuasan kerja. Perbedaanperbedaan tersebut dibawa kedunia kerja, sehingga motivasi setiap individu berbeda-beda

Budaya organisasi yang efektif dapat memberi pengaruh positif terhadap kinerja karyawan. Hasil penelitian yang dilakukan oleh Brahmansari dan Suprayetno (2008), mengatakan bahwa yang mempengaruhi kinerja karyawan adalah motivasi dan budaya organisasi Sardjito dan Muthaher (2007), Komitmen organisasi juga dapat mempengaruhi kinerja karyawan. Komitmen organisasi merupakan suatu dorongan dari dalam diri individu untuk berbuat sesuatu agar dapat menunjang keberhasilan organsasi sesuai dengan tujuan dan lebih mengutamakan kepentingan organisasi (Rudhianto, 2010), kemudian menurut Yunnus (2010) kinerja karyawan dipengaruhi oleh karakteristik individu, dan budaya organisasi.

\section{METODOLOGI PENELITIAN}

Penelitian ini dilakukan pada PT. Nusantara Auto PartsJln. Raya Medan Tamora Komplek Pergudangan Mega Trans Center. Populasi didalam penelitian ini adalah karyawan PT. Tiga Raksa Satira yang berjumlah 128 karyawan. Sampel adalah bagian dari jumlah dan karakteristik yang dimiliki oleh populasi tersebut(Sugiyono, 2013b). Penentuan jumlah sample yang diambil sebagai responden dengan menggunakan rumus slovin. Berikut adalah perhitungan jumlah sampel dengan menggunakan rumus slovin

$$
\begin{aligned}
& n=\frac{N}{N \cdot e^{2}+1} \\
& \frac{128}{128 \cdot 0,1^{2}+1}
\end{aligned}
$$




$$
n=58
$$

Pengumpulan data dalam instrument ini menggunakan angket (Questioner), adalah teknik pengumpulan data yang dilakukan dengan cara memberi seperangkat pertanyaan atau pertanyaan tertulis dalam bentuk angket kepada responden untuk dijawabnya yang ditujukan kepada parakaryawan PT. Nusantara Auto Partsdengan menggunakan skala likert dalam bentuk checklist. Teknik analisis yang digunakan dalam penelitian ini adalah analisis data kuantitatif, yakni menguji dan menganalisis data dengan perhitungan angka-angka dan kemudian menarik kesimpulan dari pengujian tersebut dengan alat uji korelasi product moment dan korelasi berganda tetapi dalam praktiknya pengolahan data penelitian ini tidak diolah secara manual,namun menggunakan software statistik SPSS

\section{HASIL DAN PEMBAHASAN}

\section{Uji Hipotesis}

\section{Regresi Linier Berganda}

Analisis data dalam penelitian ini menggunakan analisis regresi berganda. Dalam penelitian ini terdapat dua variabel independen, yaitu budaya organisasi dan karakteristik individuserta satu variabel dependen yaitu Komitmen organisasi. Adapun rumus dari regresi linier berganda adalah sebagai berikut :

Tabe 1. Regresi Berganda

\begin{tabular}{|c|c|c|c|c|c|c|}
\hline \multirow{2}{*}{\multicolumn{2}{|c|}{ Model }} & \multicolumn{2}{|c|}{ Unstandardized Coefficients } & \multirow{2}{*}{$\begin{array}{c}\begin{array}{c}\text { Standardized } \\
\text { Coefficients }\end{array} \\
\text { Beta }\end{array}$} & \multirow[b]{2}{*}{$\mathrm{t}$} & \multirow[b]{2}{*}{ Sig. } \\
\hline & & $\mathrm{B}$ & Std. Error & & & \\
\hline \multirow[t]{3}{*}{1} & (Constant) & 11.335 & 4.927 & & 2.301 & .027 \\
\hline & $\begin{array}{l}\text { Budaya } \\
\text { organisasi }\end{array}$ & .102 & .168 & .751 & 6.606 & .000 \\
\hline & $\begin{array}{l}\text { Karakteristik } \\
\text { individu }\end{array}$ & .195 & .167 & .885 & 7.144 & .000 \\
\hline
\end{tabular}

Sumber: Hasil Penelitian, 2021

Berdasarkan tabel $=$ di atas maka persamaan regresi linier berganda dalam penelitian ini adalah sebagai berikut :

Keterangan:

$$
\mathrm{Y}=11,335+0,102 \mathrm{X} 1+0,195 \mathrm{X} 2
$$

$\mathrm{Y}=$ Komitmen organisasi

$\mathrm{a}=$ konstanta

$\mathrm{X} 1$ = Budaya organisasi

$\mathrm{X} 2$ = Karakteristik individu

1. Pada model regresi ini, nilai konstanta yang tercantum sebesar 11,335 dapat diartikan jika variabel bebas dalam model diasumsikan sama dengan nol, secara rata-rata variabel diluar model tetap akan meningkatkan Komitmen organisasi sebesar 11,335 satu-satuan atau dengan kata lain jika variabel budaya organisasi dan karakteristik individu tidak ditingkatkan, maka Komitmen organisasi masih sebesar 11,335.

2. Nilai koefisien regresi b1 sebesar 0,102 pada penelitian ini dapat diartikan bahwa variabel Budaya organisasi (X1) memiliki hubungan yang positif terhadap Komitmen organisasi pada ASN di PT. Nusantara Auto Parts. Hal ini menunjukkan bahwa ketika Budaya organisasi mengalami peningkatan sebesar satu satuan, maka akan meningkatkan Komitmen organisasi sebesar 0,102 .

3. Nilai koefisien regresi b2 sebesar 0,102 pada penelitian ini dapat diartikan bahwa variabel karakteristik individu (X2) memiliki hubungan yang positif terhadap Komitmen organisasi pada ASN di PT. Nusantara Auto Parts. Hal ini menunjukkan bahwa ketika karakteristik individu 
mengalami peningkatan sebesar satu satuan, maka akan meningkatkan Komitmen organisasi sebesar 0,102

\section{Koefisien Determinasi}

Koefisien determinasi $\left(\mathrm{R}^{2}\right)$ digunakan untuk melihat kemampuan modeldalam menjelaskan variabel independen terhadap variabel dependen darimodel yang dibangun. Berdasarkan hasil pengujian statistik untuk model dengan variabel independen.

Tabel 2. Nilai Koefisien Determinasi

\begin{tabular}{|l|r|r|r|}
\hline Model & \multicolumn{1}{|c|}{$\mathrm{R}$} & R Square & \multicolumn{1}{c|}{$\begin{array}{c}\text { Adjusted R } \\
\text { Square }\end{array}$} \\
\hline 1 & .836 & .699 & .682 \\
\hline
\end{tabular}

Koefisien determinasi dengan nilai Adjusted $R$ Square sebesar 0,836 berarti variabel independen mampu menjelaskan variasi variabel dependen hanya sebesar $83.6 \%$, sisanya sebesar $16.4 \%$ diterangkan oleh variabel lain di luar model yang terangkum dalam error

\section{Uji t}

Uji t digunakan untuk menguji signifikansi konstanta dan setiap variabel independennya. Berdasarkan hasil pengolahan SPSS versi 22, diperoleh hasil sebagai berikut :

Tabel 3. Uji t

\begin{tabular}{|c|c|c|c|c|c|c|}
\hline \multirow{2}{*}{\multicolumn{2}{|c|}{ Model }} & \multicolumn{2}{|c|}{ Unstandardized Coefficients } & \multirow{2}{*}{$\begin{array}{l}\text { Standardized } \\
\text { Coefficients } \\
\text { Beta }\end{array}$} & \multirow[b]{2}{*}{$\mathrm{t}$} & \multirow[b]{2}{*}{ Sig. } \\
\hline & & $\mathrm{B}$ & Std. Error & & & \\
\hline \multirow[t]{3}{*}{1} & (Constant) & 11.335 & 4.927 & & 2.301 & .027 \\
\hline & $\begin{array}{l}\text { Budaya } \\
\text { organisasi }\end{array}$ & .102 & .168 & .751 & 6.606 & .000 \\
\hline & $\begin{array}{l}\text { Karakteristik } \\
\text { individu }\end{array}$ & .195 & .167 & .885 & 7.144 & .000 \\
\hline
\end{tabular}

Dari tabel regresi dapat dilihat besarnya thitung untuk variable:

1. Budaya organisasi sebesar 6.606 dengan nilai signifikan 0,000 , sedangkan $t_{\text {tabel }}$ adalah 1,68 , sehingga $t_{\text {hitung }}<t_{\text {tabel }}(6.606>1,68)$, maka budaya organisasi menunjukkan angka $<0,05$ $(0,000<0,05)$, maka Ha diterima dan H0 ditolak, artinya budaya organisasi berpengaruh signifikan terhadap komitmen organisasi.

2. Karakteristik individu sebesar 7,144 dengan nilai signifikan 0,000 , sedangkan $t_{\text {tabel }}$ adalah 1,68 , sehingga $t_{\text {hitung }}<t_{\text {tabel }}(7.144>1,68)$, maka budaya organisasi menunjukkan angka $<0,05$ $(0,000<0,05)$, maka Ha diterima dan H0 ditolak, artinya karakteristik individu berpengaruh signifikan terhadap komitmen organisasi karyawan.

\section{Uji F}

Tabel 4. Uji F

\begin{tabular}{|ll|r|r|r|r|r|}
\hline \multicolumn{1}{|c|}{} & \multicolumn{1}{|c|}{ Sum of } & & & & \\
Model & Squares & df & Mean Square & F & Sig. \\
\hline 1 & Regression & 1582.030 & 2 & 791.015 & 41.716 & $.000^{\mathrm{b}}$ \\
& Residual & 682.637 & 36 & 18.962 & & \\
Total & 2264.667 & 38 & & & \\
\hline
\end{tabular}

a. Dependent Variable: Komitmen organisasi

b. Predictors: (Constant), Karakteristik individu, Budaya organisasi 
Berdasarkan hasil uji $\mathrm{F}$ diatas maka dapat dilihat bahwa $\mathrm{F}_{\text {hitung }}>\mathrm{F}_{\text {tabel }}(41.716>3.26)$ dan nilai $0.000<0.05$ hal ini menunjukkan bahwa secara simultan budaya organisasi dan karakteristik individu kerja berpengaruh signifikan terhadap komitmen organisasi

\section{PEMBAHASAN HASIL PENELITIAN}

\section{Pengaruh Budaya organisasi Terhadap Komitmen organisasi}

Dari tabel regresi dapat dilihat Budaya organisasi sebesar 6.606 dengan nilai signifikan 0,000, sedangkan $t_{\text {tabel }}$ adalah 1,68 , sehingga $t_{h i t u n g}<t_{t a b e l}(6.606>1,68)$, maka budaya organisasi menunjukkan angka $<0,05(0,000<0,05)$, maka Ha diterima dan $\mathrm{H} 0$ ditolak, artinya budaya organisasi berpengaruh signifikan terhadap komitmen organisasi. Hal ini menunjukkan bahwa budaya organisasi dipengaruh oleh besarnya budaya organisasi yang diterima oleh karyawan. Budaya organisasi merupakan suatu fungsi Manajemen yang perlu dilaksanakan terus-menerus dalam rangka pembinaan ketenagaan dalam organisasi. Secara spesifik, proses perbaikan budaya organisasi merupakan tindakan (upaya), yang dilaksanakan secara berkesinambungan, bertahap dan terpadu. Tiap proses perbaikan budaya organisasi harus terarah untuk mencapai tujuan tertentu terkait dengan upaya pencapaian tujuan organisasi.

Budaya organisasi kerja sangat penting bagi tenaga kerja untuk bekerja lebih menguasai dan lebih terhadap pekerjaan yang dijabat atau akan dijabat kedepan. Tidak terlalu jauh dalam budaya organisasi sering dilakukan sebagai upaya meningkatkan komitmen organisasi para pegawai yang dianggap belum mampu untuk mengemban pekerjaannya karena faktor perkembangan kebutuhan masyarakat.

Budaya organisasimerupakan aktivitas operasional yang sangat penting dalam perusahaan. Kualitas dari karyawan dapat dikembangkan didalam budaya organisasi itu sendiri. Untuk menghasilkan karyawan yang memiliki pengetahuan keahlian dan sikap mental yang sesuai dengan yang dibutuhkan perusahaan maka penyelenggaraan budaya organisasi merupakan suatu keharusan. Melalui adanya budaya organisasi akan meningkatkan komitmen organisasi karyawan sehingga dapat menunjang keberhasilan perusahaan.

Hasil penelitian ini sesuai dengan penelitian terdahulu yang menunjukkan bahwa budaya organisasi berpengaruh terhadap komitmen organisasi (Rustini \& Suardikha, 2015), (Wardhani et al., 2016)

\section{Pengaruh Karakteristik individu Kerja Terhadap Komitmen organisasi}

Dari tabel regresi dapat dilihat besarnya thitung untuk variabel karakteristik individu sebesar 7,144 dengan nilai signifikan 0,000, sedangkan $t_{\text {tabel }}$ adalah 1,68 , sehingga $t_{h i t u n g}<t_{t a b e l}(7.144>1,68)$, maka budaya organisasi menunjukkan angka $<0,05(0,000<0,05)$, maka Ha diterima dan H0 ditolak, artinya karakteristik individu berpengaruh signifikan terhadap komitmen organisasi.

Karakteristik individu kerja sangat penting dalam menjalankan usaha suatu organisasi. Dengan memperoleh karakteristik individu kerja, maka tugas yang dibebankan dapat dikerjakan dengan baik. Sedangkan karakteristik individu kerja jelas sangat mempengaruhi komitmen organisasi karyawan karena dengan mempunyai karakteristik individu kerja, maka komitmen organisasipun akan meningkat. Karakteristik individu kerja bekerja yang dimiliki seseorang, kadang -kadang lebih dihargai daripada tingkat pendidikan yang menjulang tinggi.

Karyawan mempunyai karakteristik individu kerja tinggi makadapat meningkatkan komitmen organisasi karyawan. Artinya semakin baik karakteristik individu kerja seorang karyawan maka komitmen organisasi karyawan akan semakin tinggi pula. Sebaliknya semakin sedikit karakteristik individu kerja karyawan maka komitmen organisasi karyawan juga semakin rendah. Indikator dari karakteristik individu kerja adalah Lama waktu/masa kerja, Tingkat pengetahuan, Pendidikan, Penataran

Lama waktu/masa kerja Ukuran tentang lama waktu atau masa kerja yang telah di tempuh seseorang dapat memahami tugas-tugas suatu pekerjaan dan telah melaksanakan dengan baik. Berdasarkan pendidikan yang dilaksanakan oleh seseorang, maka orang tersebut dapat memperoleh karakteristik individu kerja yang lebih banyak dari sebelumnya. Melalui kegiatan penataran dan sejenisnya, maka sesorang akan memperoleh karakteristik individu kerja untuk 
diterapkan sesuai dengan kemampuannya. Pengetahuan merujuk pada konsep, prinsip, prosedur, kebijakan atau informasi lain yang dibutuhkan oleh karyawan. Pengetahuan juga mencakup kemampuan untuk memahami dan menerapkan informasi pada tanggung jawab pekerjaan.

Hasil penelitian terdahulu menunjukkan bahwa karakteristik individu berpengaruh terhadap komitmen organisasi (J. Jufrizen, 2015; Pribady. N. A., 2018), (Syahputra \& Tanjung, 2020)

\section{Pengaruh Budaya organisasi dan Karakteristik individu Terhadap Komitmen} Organisasi( beri penjelasanya)

Berdasarkan hasil uji $F$ diatas maka dapat dilihat bahwa $F_{\text {hitung }}>F_{\text {tabel }}(41.716>3.26)$ dan nilai $0.000<0.05$ hal ini menunjukkan bahwa secara simultan budaya organisasi dan karakteristik individu kerja berpengaruh signifikan terhadap komitmen organisasi.

Komitmen Organisasi pegawai akan meningkat apabila didukung oleh budaya organisasi yang tinggi dari pegawai atas pekerjaannya. Pegawai tentunya memiliki kebutuhan-kebutuhan dan kepentingan - kepentingan yang harus dipenuhinya. Hal ini menjadi pendorong untuk melaksanakan kegiatan-kegiatan organisasi dengan harapan kebutuhan dan kepentingan individualnya dapat diwujudkan sehingga kegiatan yang dilakukan dapat memberikan manfaat kepada organisasi. Oleh karena itu, organisasi penting untuk memperhatikan aspek budaya organisasi agar organisasi tidak kehilangan individuindividu yang berkualitas (Murty \& Hudiwinarsih, 2012).

Faktor lain yang juga berpengaruh terhadap Komitmen Organisasi pegawai adalah Kepuasan Kerja. Pegawai yang memiliki kepuasan kerja yang tinggi memberikan kontribusi penting terhadap peningkatan Komitmen Organisasi(Budiyanto \& Oetomo, 2011).

Beberapa studi sebelumnya menyatakan bahwa Budaya organisasi berpengaruh positif dan signifikan terhadap komitmen organisasi : (Jufrizen Jufrizen et al., 2020), (Suhardi \& Syaifullah, 2017), dan (Kusuma, 2014). Budaya organisasi berpengaruh positif dan signifikan terhadap Komitmen Organisasi karyawan : (Jufrizen Jufrizen, 2017) dan (Luthans, 2006). Berdasarkan uraian tersebut maka dapat disimpulkan bahwa budaya organisasai dan karaktoristik individu berpengaruh positif dan signifikan terhadap komitmen organisasi.

\section{KESIMPULAN}

Dari hasil analisis yang telah di bahas sebelumnya, maka dapat di ambil kesimpulan sebagai berikut :Berdasarkan hasil penelitian diperoleh budaya organisasi berpengaruh signifikan terhadap komitmen organisasi. Berdasarkan hasil penelitian diperoleh karakteristik individu berpengaruh signifikan terhadap komitmen organisasi karyawan. Berdasarkan hasil uji $\mathrm{F}$ budaya organisasi dan karakteristik individu kerja berpengaruh signifikan terhadap komitmen organisasi.

\section{DAFTAR PUSTAKA}

Adriyani, P. D., \& Dewi, I. G. A. M. (2020). Pengaruh Iklim Organisasi, Motivasi Kerja, dan Stres Kerja Terhadap Kepuasan Kerja Karyawan. E-Jurnal Manajemen, 9(10), 34633485.

Ardana, I. K., Mujiati, N. W., \& Utama, I. W. M. (2012). Manajemen Sumber Daya Manusia. Yogyakarta: Graha Ilmu.

Budiyanto, \& Oetomo, H. W. (2011). The Effect of Job Motivation, Work Environment and Leadership on Organizational Citizenship Behavior, Job Satisfaction and Public Service Quality in Magetan, East Java, Indonesia. International Journal of Economics and Management Engineering, 5(3), 277-285.

Ghozali. I. (2005). Analisis Multivariat Dengan Menggunakan SPSS. Semarang: Undip.

Idrus, M. (2006). Implikasi Iklim Organisasi Terhadap Kepuasan Kerja Dan Kualitas Kehidupan Kerja Karyawan. Jurnal Psikologi Universitas Diponegoro, 3(1), 94-106.

Jufrizen, J. (2015). Pengaruh Kompensasi Dan Pengembangan Karir Terhadap Komitmen Organisasi Dengan Kepuasan Kerja Sebagai Variabel Intervening Pada PT. Perkebunan 
Nusantara III (Persero) Medan. Jurnal Ilmiah Manajemen \& Bisnis, 15(1), 37-47.

Jufrizen, Jufrizen, Farisi, S., Azhar, M. E., \& Daulay, R. (2020). Model Empiris Organizational Citizenship Behavior dan Kinerja Dosen Perguruan Tinggi Swasta di Medan. EKUITAS (Jurnal Ekonomi Dan Keuangan), 4(2), 145-165. https://doi.org/10.24034/j25485024.y2020.v4.i2.4159

Jufrizen, Jufrizen. (2017). Pengaruh kemampuan dan motivasi terhadap kinerja perawat Studi pada Rumah Sakit Umum Madani Medan. Jurnal Riset Sains Manajemen, 1(1), 27-34. https://doi.org/10.5281/zenodo.1036809

Kaswan. (2017). Psikologi Industri dan Organisasi (1st ed.). Bandung: Alfabeta, cv.

Kusuma, L. S. (2014). Pengaruh Motivasi Kerja Dan Kepuasan Kerja Terhadap Organizational Citizenship Behavior Pegawai Bri Yogyakarta. Yogyakarta: Fakultas Ekonomi Universitas Negeri Yogyakarta.

Lila Bismala, Nel Arianty, T. F. (2015). Perilaku Organisasi. Medan: UMSU Pers.

Luthans, F. (2006). Perilaku Organisasi (10th ed.). Yogyakarta: Andi Offset.

Mangkunegara. A.A.P. (2017). Manajemen Sumber Daya Manusia. Bandung: Remaja Rosda Karya.

Mangkunegara, A. A. P. (2014). Evaluasi Kinerja SDM/SM-17. Bandung: PT Refika Aditama.

Murty, W. A., \& Hudiwinarsih, G. (2012). Pengaruh Kompensasi, Motivasi Dan Komitmen Organisasional Terhadap Kinerja Karyawan Bagian Akuntansi (Studi Kasus Pada Perusahaan Manufaktur Di Surabaya). The Indonesian Accounting Review, 2(2), 215-228.

Nawawi, I. (2013). Budaya Organisasi Kepemimpinan Dan Kinerja. Jakarta: Prenamedia.

Prameswari, N. K. S., \& Suwandana, I. G. M. (2017). Pengaruh Keadilan Organisasional, Komitmen Organisasional, Dan Kepuasan Kerja Terhadap Organizational Citizenship Behavior. E-Jurnal Manajemen Unud, 6(3), 1368-1397.

Pribady. N. A. (2018). Desain dan Pengembangan Program Perencanaan karir Berbasis Kompetensi. Jakarta: kencana.

Rustini, N. K. A., \& Suardikha, I. S. (2015). Pengaruh kompensasi dan lingkungan kerja pada komitmen organisasi dan implikasinya pada kinerja pengelola anggaran (studi empiris pada satuan kerja .... Buletin Studi ....

Siagian.S.P (Ed.). (2016). MSDM (4 cet 26). Jakarta: Bumi Aksara.

Soetopo, H. (2012). Perilaku organisasi. Bandung: PT. Remaja Rosdakarya.

Sugiyono. (2010). Metode Penelitian Pendidikan Pendekatan Kuantitatif, kualitatif, dan R\&D. Bandung: Alfabeta.

Sugiyono. (2013a). Metode Penelitian Bisnis (8th ed.). Bandung: Alfabeta.

Sugiyono. (2013b). Metodologi Penelitian Kuantitatif dan Kualitatif. Bandung: Alfabeta.

Suhardi, \& Syaifullah. (2017). Pengaruh Motivasi, Kompetensi, Lingkungan Kerja, Kompensasi Terhadap Organizational Citizenship Behavior Dan Kinerja Karyawan Asuransi Jiwa Di Provinsi Kepulauan Riau. Jurnal Benefita, 2(1), 55-71.

Sutrisno, E. (2010). Manajemen Sumber Daya Manusia. Jakarta: kencana.

Suwanto, Priansyah, \& Juni, D. (2011). Manajemen SDM dalam Organisasi Publik dan Bisnis. Bandung: Alfabeta.

Syahputra, M. D., \& Tanjung, H. (2020). Pengaruh Kompetensi, Pelatihan dan Pengembangan Karir Terhadap Kinerja Karyawan. Maneggio : Jurnal Ilmiah Magister Manajemen, 3(2), 283-295.

Verianto, D. (2018). Pengaruh Motivasi Kerja Intrinsik Dan Keadilan Prosedural Terhadap Organizational Citizenship Behavior (OCB) Dan Kinerja Karyawan KPP Pratama Purwokerto. Jurnal Ekonomi, Bisnis, Dan Akuntansi (JEBA), 20(3), 1-15.

Wardhani, A. P., Hasiolan, L. B., \& Minarsih, M. M. (2016). Pengaruh Lingkungan Kerja, Komunikasi Dan Kepemimpinan Terhadap Kinerja Pegawai ( Studi Kasus Di Dinas Kebudayaan Dan Pariwisata Kota Semarang). Journal Of Management, 2(2). 